\title{
Health care utilization and expenditures among Medicaid beneficiaries with neuropathic pain following spinal cord injury
}

This article was published in the following Dove Press journal: Journal of Pain Research

I July 2014

Number of times this article has been viewed

Jay M Margolis'

Paul Juneau'

Alesia Sadosky ${ }^{2}$

Joseph C Cappelleri ${ }^{3}$

Thomas N Bryce ${ }^{4}$

Edward C Nieshoff ${ }^{5}$

'Truven Health Analytics, Bethesda, MD, USA; ${ }^{2}$ Pfizer Inc., New York, NY, USA; ${ }^{3}$ Pfizer Inc., Groton, CT, USA;

${ }^{4}$ Department of Rehabilitation Medicine, The Icahn School of Medicine at Mount Sinai, New York, NY, USA; ${ }^{5}$ Department of Physical Medicine and Rehabilitation, Wayne State University School of Medicine, Detroit, MI, USA
Correspondence: Jay M Margolis Truven Health Analytics, 332 Bryn Mawr Ave, Bala Cynwyd, PA 19004, USA

$\mathrm{Tel}+\mathrm{I} 6106674718$

Fax + I 6106674718

Email jay.margolis@truvenhealth.com
Background: The study aimed to evaluate health care resource utilization (HRU) and costs for neuropathic pain ( $\mathrm{NeP}$ ) secondary to spinal cord injury ( $\mathrm{SCI}$ ) among Medicaid beneficiaries.

Methods: The retrospective longitudinal cohort study used Medicaid beneficiary claims with SCI and evidence of NeP (SCI-NeP cohort) matched with a cohort without NeP (SCI-only cohort). Patients had continuous Medicaid eligibility 6 months pre- and 12 months postindex, defined by either a diagnosis of central NeP (ICD-9-CM code 338.0x) or a pharmacy claim for an NeP-related antiepileptic or antidepressant drug within 12 months following first SCI diagnosis. Demographics, clinical characteristics, HRU, and expenditures were compared between cohorts.

Results: Propensity score-matched cohorts each consisted of 546 patients. Postindex percentages of patients with physician office visits, emergency department visits, SCI- and pain-related procedures, and outpatient prescription utilization were all significantly higher for SCI-NeP $(P<0.001)$. Using regression models to account for covariates, adjusted mean expenditures were US $\$ 47,518$ for SCI-NeP and US $\$ 30,150$ for SCI only, yielding incremental costs of US\$17,369 (95\% confidence interval US $\$ 9,753$ to US $\$ 26,555)$ for SCI-NeP. Factors significantly associated with increased cost included SCI type, trauma-related SCI, and comorbidity burden.

Conclusion: Significantly higher HRU and total costs were incurred by Medicaid patients with NeP secondary to SCI compared with matched SCI-only patients.

Keywords: spinal cord injuries, burden of illness

\section{Introduction}

Approximately 273,000 individuals in the US are living with a spinal cord injury (SCI), and many are disabled; $11.6 \%$ are employed 1 year postinjury and $35.2 \%$ are employed 20 years postinjury. ${ }^{1}$ Pain is a frequent complication of SCI that has been reported to develop in up to $96 \%$ of patients subsequent to their injury, ${ }^{2}$ and substantially adds to the patient burden by adversely impacting patients' activities of daily living, quality of life, and social functioning. . $^{3,4}$

While post-SCI pain can be categorized as nociceptive (musculoskeletal, visceral, or other nociceptive), neuropathic (at-level or below-level of injury), other pain, or unknown pain, ${ }^{5}$ neuropathic pain $(\mathrm{NeP})$ develops in about $50 \%$ of SCI patients. This $\mathrm{NeP}$ results from a lesion or disease of the somatosensory nervous system related to the injury ${ }^{6,7}$ and increases the complexity of SCI management since NeP is challenging to treat. ${ }^{8}$

Recommendations for the pharmacologic management of SCI-NeP include antidepressants, antiepileptic drugs (AEDs), opioids, and intrathecal medications, ${ }^{9-11}$ 
and in the US, only pregabalin, an AED, has received approval by the US Food and Drug Administration for the treatment of NeP associated with SCI. ${ }^{12}$ Since complete pain reduction is seldom attained, the main goal of treatment is to reduce pain to a level considered acceptable by the patient.

Although studies have evaluated the treatment of pain following SCI, recent data on the economic burden of SCI, specifically for SCI-associated NeP, are limited. Direct and indirect costs for hospitalization and rehabilitation in the US, including lifelong direct costs, have been measured following SCI in some recent studies. ${ }^{1,13-17}$ A 2007 study of US Veteran Health Administration patients with a minimum duration of SCI of 2 years showed average annual costs ranging from $\$ 17,561$ to $\$ 28,334$, depending on level and completeness of SCI. ${ }^{18}$ In the only study that estimated the direct medical costs among patients with SCI-NeP, overall annualized direct medical costs of $\$ 8,636$ per patient were reported. ${ }^{19}$ That study, which recruited the population from community-based physician practices, stratified patients by self-reported pain severity and found that SCI-NeP costs increased with greater pain, with the highest costs among those with severe pain $(\$ 11,666)$. However, it is likely that not all SCI survivors are covered by private health insurance at the time of injury. One option to fill this coverage gap is the US Medicaid program, which provides financial assistance for medical and health-related services to more than 8 million disabled individuals. ${ }^{20}$ Thus, the current retrospective, longitudinal study was undertaken to evaluate health care resource utilization (HRU) and its associated costs, specifically among Medicaid beneficiaries with NeP secondary to SCI.

\section{Materials and methods Data source}

Data for this analysis were derived from administrative medical and pharmacy claims in the Truven Health Analytics MarketScan ${ }^{\circledR}$ Multi-state Medicaid Database between January 1, 2005 and June 30, 2012. This database includes complete longitudinal records of inpatient services, outpatient services, long-term care, nursing home, home health care, and prescription drug claims covered under Medicaid programs in 12 geographically diverse states. All database records are de-identified and fully compliant with US patient confidentiality requirements, including the Health Insurance Portability and Accountability Act (HIPAA) of 1996. The databases have been evaluated and certified by an independent third party to be in compliance with the conditions set forth in Sections 164.514 (a)-(b)1ii of the HIPAA privacy rule regarding the determination and documentation of statistically de-identified data. There was no interaction with any subjects, and the databases do not include any individually identifiable data (eg, no names, addresses, social security or medical record numbers, or any other identifiers).

\section{Subject selection and study period}

From the available data, two cohorts were formed of patients who met the eligibility criteria for each cohort; one cohort consisted of SCI patients with associated NeP (SCI-NeP), and the second cohort consisted of SCI patients without NeP (SCI only). The SCI-only cohort served as a control to help determine the contribution of $\mathrm{NeP}$ to HRU and costs during SCI management.

Initial identification of patients with SCI was based on an inpatient or outpatient medical claim for SCI between January 1, 2006 and June 30, 2011 using ICD-9-CM diagnosis codes of 344.0x (quadriplegia and quadriparesis), 344.1x (paraplegia), 344.6x (cauda equina syndrome), 806.xx (fracture of vertebral column with SCI), or 952.xx (SCI without evidence of spinal bone injury) in any position; patients were required to be $\geq 18$ years of age at the date of the first SCI claim. A minimum of 6 months of continuous medical and pharmacy Medicaid eligibility was required prior to the first SCI claim with the SCI diagnosis. From this population, the SCI-NeP cohort was identified by either a diagnosis of central NeP (ICD-9-CM code 338.0x) or a pharmacy claim for an NeP-related AED or NeP-related antidepressant drug within 12 months following first SCI diagnosis.

The use of NeP-related medications as a proxy to identify $\mathrm{NeP}$ was initiated because the central $\mathrm{NeP}$ diagnostic code is rarely used in medical claims. The NeP-related AEDs were carbamazepine, gabapentin, lamotrigine, oxcarbazepine, phenytoin, pregabalin, topiramate, and valproic acid; NeP-related antidepressants included the serotoninnorepinephrine inhibitors (SNRIs) duloxetine, venlafaxine, milnacipran, and desvenlafaxine and the tricyclic antidepressants (TCA) amitriptyline, desipramine, doxepin, imipramine, and nortriptyline. Medications for defining SCI-NeP were chosen based on a literature review and practitioner recommendations, ${ }^{6,8-11,21}$ and patients in this cohort could not have NeP-related claims, including for NeP-related AEDs or antidepressants, during the 6 months before the first SCI diagnosis.

The date of the first NeP diagnosis according to the above criteria was the SCI-NeP index date. All SCI-NeP patients were required to have continuous Medicaid enrollment for 6 months preindex (baseline) and 12 months postindex. 
Exclusion criteria included a diagnosis of any of the following conditions for which drugs prescribed for the treatment of SCI-NeP may also be used: epilepsy (ICD-9-CM codes 345.xx or 780.39), amyotrophic lateral sclerosis (ICD-9-CM code 335.20), multiple sclerosis (ICD-9-CM code 340.xx), diabetic peripheral neuropathy (ICD-9-CM codes 250.6x, $357.2 x$ ), or postherpetic neuralgia (ICD-9-CM code $053.1 \mathrm{x}$ ). Medical or pharmacy claims for medications used to treat multiple sclerosis (intramuscular or subcutaneous interferon beta-1a, interferon beta-1b, glatiramer acetate, fingolimod) or amyotrophic lateral sclerosis (riluzole) anytime during the study period were also cause for exclusion.

Patients included in the SCI-only cohort were required to meet the same eligibility criteria as the SCI-NeP patients except without the $\mathrm{NeP}$ diagnosis and to have no use of the NeP-related medications (AEDs or antidepressants) at any time during the study period. Index dates for the SCI-only cohort were assigned according to the date of their SCI diagnosis and the number of days between their diagnosis and the index date for a randomly selected SCI-NeP patient. Propensity score matching was conducted using a logistic regression model to predict the probability that a patient will develop NeP.22 This model resulted in a propensity score based on preindex characteristics including age, sex, health plan type, index year, Deyo-Charlson Comorbidity Index (DCI) score, ${ }^{23}$ number of three-digit ICD-9-CM codes, number of unique drugs, specific type of SCI diagnosis, presence of specific comorbid conditions, use of specific concomitant medications, and preindex all-cause health care expenditures. The purpose of matching the propensity score is to ensure similarity between the groups (SCI-NeP and SCI only) with respect to observed covariates, so that observed differences in outcomes can be more confidently ascribed to the distinguishing factor $(\mathrm{NeP})$; therefore, the propensity score matching adjusts for the observed covariates in the model. Matching from the SCI pool was performed without replacement using an algorithm of one-to-one nearest neighbor matching. ${ }^{24}$

\section{Outcome measures}

Demographic and clinical characteristics were captured during the preindex baseline period for both cohorts. In addition to type of SCI and specified comorbidities, clinical characteristics included the following comorbidity indexes: DCI, number of unique three-digit ICD-9-CM codes, and number of unique outpatient medications. Clinical characteristics were also captured during the postindex period. To identify traumatic SCI in the absence of a specific
ICD-9-CM code, the variable "trauma-related SCI" was created as a proxy by searching the medical claims of each included patient for a diagnosis code of vertebral column fracture (806.xx) or late effects of SCI (907.2x) at any time on or after the initial SCI diagnosis. ${ }^{25}$

Categories of HRU and expenditures included inpatient admissions, emergency department (ED) visits, physician office visits, SCI and pain-related procedures, and outpatient prescriptions. These resources were measured during the 12-month postindex period for SCI-NeP and SCI-only patients. Expenditures were determined using the gross covered payments on medical and pharmacy claims, ie, the amount eligible for payment to the provider before applying deductibles, copayments, or coordination of benefits. Payments in all years were adjusted to 2012 US dollars using the Medical Care component of the Bureau of Labor Statistics Consumer Price Index. ${ }^{26}$

\section{Statistical analysis}

Patient demographics, clinical characteristics, and 6-month preindex total health care expenditures were summarized descriptively. Postindex use of concomitant medications, SCI-related procedures, pain-related procedures, resource utilization, and costs were assessed using univariate and bivariate descriptive summaries. Statistical significance, with a value of 0.05 specified a priori, between the SCI-NeP and SCI-only cohorts was tested using chi-square or Fisher's exact test for categorical variables and two-sample Student's $t$-tests for quantitative variables.

Generalized linear models (GLMs) were used to further adjust the propensity score-matched results for effects of potential confounding or risk factors by relating health care resource and economic outcomes with patient demographic and clinical characteristics. In these models, binary outcomes (ie, hospital admissions and ED visits) were fitted with a GLM using a binomial distribution and its canonical link, and count outcomes (ie, number of hospital admissions or ED visits per patient) were modeled using a Poisson or negative binomial distribution; when the number of events was zero for many individuals, the corresponding "zero-inflated" version was applied. ${ }^{27}$ Cost data were modeled using a traditional GLM, assuming an underlying gamma distribution and a log link, and an ordinary least squares model fit to the log transformed positive expenditures retransformed to predict costs, with bootstrapping for standard errors and confidence intervals. ${ }^{28}$ Analyses were conducted using SAS version 9.2 (SAS Institute Inc., Cary, NC, USA). 


\section{Results}

The SCI-NeP and SCI-only cohorts each consisted of 546 patients who met all eligibility criteria; incremental attrition is shown in Table 1. Initiation of NeP-related AEDs $(\mathrm{n}=351 ; 64.3 \%)$ was the most common index event, followed by NeP-related TCAs ( $\mathrm{n}=115 ; 21.1 \%)$, NeP-related SNRIs $(n=76 ; 13.9 \%)$, and four patients $(0.7 \%)$ with central $\mathrm{NeP}$ diagnosis. Of the 351 AED index events, most were with gabapentin $(n=262 ; 74.6 \%)$, followed by pregabalin $(n=53$; $15.1 \%)$ and topiramate $(n=17 ; 4.8 \%)$. Index events with TCAs were primarily with amitriptyline ( 83 of $115 ; 72.2 \%$ ) while initiation of NeP-related SNRIs was primarily with duloxetine and venlafaxine, $57.9 \%$ and $34.2 \%$ of the SNRI index events, respectively.

As shown in Table 2, the SCI-NeP cohort was primarily female $(56.0 \%)$ and white $(58.6 \%)$, with an average age of 40.1 years (standard deviation [SD] 13.8), and the SCI-only cohort was also primarily female (54.8\%) and white (58.6\%), with an average age of 41.5 (SD 16.0) years. None of these differences was statistically significant. Both cohorts were similarly comprised of predominantly urban populations

Table I Sample size attrition table

\begin{tabular}{|c|c|c|}
\hline Attrition criterion & $\mathbf{N}$ & Percent \\
\hline $\begin{array}{l}\text { At least one spinal cord injury }(\mathrm{SCl}) \text { diagnosis } \\
\text { during January I, 2006-June } 30,201 \text { I }\end{array}$ & 46,931 & 100.0 \\
\hline $\begin{array}{l}\text { Continuous medical and pharmacy benefit } \\
\text { enrollment } 6 \text { months prior to first } \mathrm{SCl} \text { diagnosis }\end{array}$ & 19,449 & 41.4 \\
\hline $\begin{array}{l}\text { No } \mathrm{SCl} \text { diagnosis during the } 6 \text { months before } \\
\text { the first } \mathrm{SCl} \text { diagnosis }\end{array}$ & 16,774 & 35.7 \\
\hline $\begin{array}{l}\text { No neuropathic pain }(\mathrm{NeP}) \text { diagnosis or } \mathrm{NeP} \text { - } \\
\text { related drugs during the } 6 \text { months before the } \\
\text { first } \mathrm{SCl} \text { diagnosis }\end{array}$ & 11,705 & 24.9 \\
\hline $\begin{array}{l}\text { NeP diagnosis or NeP-related drug within } \\
\text { I } 2 \text { months following first } \mathrm{SCl} \text { diagnosis } \\
\text { (NeP index event) })^{\mathrm{a}}\end{array}$ & 1,603 & 3.4 \\
\hline $\begin{array}{l}\text { Continuous medical and pharmacy benefit } \\
\text { enrollment } 6 \text { months prior to } \mathrm{NeP} \text { index event }\end{array}$ & $\mathrm{I}, 542$ & 3.3 \\
\hline $\begin{array}{l}\text { Continuous medical and pharmacy benefit } \\
\text { enrollment } 12 \text { months following NeP index event }\end{array}$ & 1,116 & 2.4 \\
\hline $\begin{array}{l}\text { No evidence of seizure disorders, multiple } \\
\text { sclerosis, amyotrophic lateral sclerosis, diabetic } \\
\text { peripheral neuropathy, postherpetic neuralgia, } \\
\text { or related medications during pre or postindex } \\
\text { periods }\end{array}$ & 708 & 1.5 \\
\hline $\begin{array}{l}\text { Age } \geq 18 \text { years of age at date of first found } \mathrm{SCl} \\
\text { event }\end{array}$ & 581 & 1.2 \\
\hline $\begin{array}{l}\text { Patients included in final } \mathrm{SCl}-\mathrm{NeP} \text { cohort after } \\
\text { propensity score matching process }{ }^{\mathrm{a}}\end{array}$ & 546 & 1.2 \\
\hline
\end{tabular}

Table 2 Patient demographic characteristics at index date

\begin{tabular}{|c|c|c|c|}
\hline Variable & $\begin{array}{l}\mathrm{SCl}-\mathrm{NeP} \\
\mathrm{n}=546\end{array}$ & $\begin{array}{l}\text { SCI only } \\
n=546\end{array}$ & $P$ \\
\hline Age, years, mean (SD) & $40.1(13.8)$ & $41.5(16.0)$ & 0.142 \\
\hline Age groups, years, n (\%) & & & 0.0004 \\
\hline $18-24$ & $103(18.9)$ & $101(18.5)$ & \\
\hline $25-34$ & $124(22.7)$ & $120(22.0)$ & \\
\hline $35-44$ & $104(19.0)$ & $76(13.9)$ & \\
\hline $45-54$ & $128(23.4)$ & $105(19.2)$ & \\
\hline$\geq 55$ & $87(I 5.9)$ & $144(26.4)$ & \\
\hline Male, n (\%) & $240(44.0)$ & $247(45.2)$ & 0.670 \\
\hline Race, n (\%) & & & 0.817 \\
\hline White & $320(58.6)$ & $320(58.6)$ & \\
\hline Black & $149(27.3)$ & I 58 (28.9) & \\
\hline Other & $77(14.1)$ & $68(12.5)$ & \\
\hline Population density, n (\%) & & & 0.137 \\
\hline Urban & $384(70.3)$ & $406(74.4)$ & \\
\hline Rural & $162(29.7)$ & $140(25.6)$ & \\
\hline Insurance plan, n (\%) & & & 0.005 \\
\hline Comprehensive & $310(56.8)$ & 305 (55.9) & \\
\hline $\begin{array}{l}\text { Health maintenance } \\
\text { organization }\end{array}$ & $|4|(25.8)$ & $157(28.8)$ & \\
\hline Point-of-service & $83(15.2)$ & $84(15.4)$ & \\
\hline Other & $12(2.2)$ & 0 & \\
\hline $\begin{array}{l}\text { Total health care } \\
\text { expenditures, mean }(\mathrm{SD})^{\mathrm{a}}\end{array}$ & $\begin{array}{l}\$ 48,311 \\
(\$ 108,389)\end{array}$ & $\begin{array}{l}\$ 38,162 \\
(\$ 89,022)\end{array}$ & 0.091 \\
\hline
\end{tabular}

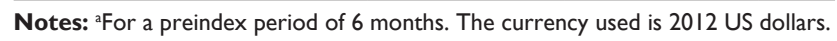
Abbreviations: NeP, neuropathic pain; SCl, spinal cord injury; SD, standard deviation.

(SCI-NeP 70.3\%, SCI only 74.4\%; $P=0.137$ ), and small but significant differences were observed for the types of insurance plans (Table 2).

Although the proportion of patients with each type of SCI was similar between cohorts, trauma-related SCI diagnosis codes were significantly more common in the SCI-NeP cohort (30.4\% versus $22.3 \% ; P=0.003$ ) (Table 3 ). Both cohorts were characterized by a substantial comorbidity burden at baseline, as indicated by the mean values for the comorbidity indexes and the prevalence of specific conditions. Musculoskeletal pain was present in half of both cohorts and gastrointestinal conditions in approximately one-third. Except for long-acting opioids, which were used by a significantly higher proportion of SCI-NeP patients during the preindex period (11.4\% versus $7.7 \% ; P=0.039)$, preindex medication utilization was not significantly different between the cohorts (Table 3 ). However, spine decompression and stabilization procedures were significantly higher preindex in the SCI-NeP cohort relative to SCI only, $12.8 \%$ versus $7.0 \%(P=0.001)$ and $10.4 \%$ versus $6.2 \%(P=0.012)$, respectively.

Relative to the preindex period, there was greater use of all pain-related medication classes during the 12-month follow-up period in the SCI-NeP cohort, with short-acting 
Table 3 Baseline (preindex) clinical characteristics of the study cohorts

\begin{tabular}{|c|c|c|c|}
\hline Variable & $\begin{array}{l}\mathrm{SCl}-\mathrm{NeP} \\
n=546\end{array}$ & $\begin{array}{l}\text { SCI only } \\
n=546\end{array}$ & $\mathbf{P}$ \\
\hline \multicolumn{4}{|l|}{ Type of SCI, \% } \\
\hline Quadriplegia/quadriparesis & 20.3 & 23.8 & 0.166 \\
\hline Paraplegia & 31.1 & 35.0 & 0.177 \\
\hline Cauda equina syndrome & 10.6 & 11.5 & 0.630 \\
\hline Vertebral column fracture & 17.0 & 19.6 & 0.273 \\
\hline $\mathrm{SCl}$ without spinal bone injury & 29.1 & 32.4 & 0.238 \\
\hline Trauma-related $\mathrm{SCl}^{\mathrm{b}}$ & 30.4 & 22.3 & 0.003 \\
\hline \multicolumn{4}{|l|}{ Comorbidity indexes, mean (SD) } \\
\hline $\begin{array}{l}\text { Deyo-Charlson Comorbidity } \\
\text { Index }\end{array}$ & $1.7(2.0)$ & $1.8(2.2)$ & 0.420 \\
\hline ICD-9-CM diagnoses ${ }^{c}$ & $18.0(10.7)$ & $17.6(10.4)$ & 0.466 \\
\hline Outpatient medications $^{d}$ & $10.2(8.8)$ & $10.6(8.4)$ & 0.553 \\
\hline \multicolumn{4}{|l|}{ Comorbid conditions, \% } \\
\hline Musculoskeletal pain & 49.8 & 50.0 & 0.952 \\
\hline Gastrointestinal conditions ${ }^{e}$ & 36.3 & 35.5 & 0.801 \\
\hline Hypertension & 32.2 & 34.1 & 0.520 \\
\hline Substance abuse & 28.2 & 26.7 & 0.588 \\
\hline Respiratory conditions ${ }^{f}$ & 22.3 & 20.9 & 0.556 \\
\hline Renal/bladder conditions ${ }^{g}$ & 21.4 & 20.1 & 0.602 \\
\hline Anxiety & 17.4 & 15.0 & 0.286 \\
\hline Diabetes & 14.3 & 16.8 & 0.243 \\
\hline $\begin{array}{l}\text { Arthritis (osteoarthritis and } \\
\text { rheumatoid arthritis) }\end{array}$ & 12.6 & 13.6 & 0.654 \\
\hline Depression & 10.8 & 8.2 & 0.149 \\
\hline Insomnia/sleep disorders & 7.9 & 7.5 & 0.820 \\
\hline Atherosclerosis & 6.4 & 6.4 & 1.000 \\
\hline Deep-vein thrombosis & 5.7 & 4.8 & 0.496 \\
\hline \multicolumn{4}{|l|}{ Medications, \% } \\
\hline Opioid analgesics - short-acting & 68.5 & 70.1 & 0.555 \\
\hline Muscle relaxants & 35.9 & 34.4 & 0.612 \\
\hline Anxiolytics & 34.8 & 32.4 & 0.405 \\
\hline NSAIDs & 32.6 & 33.2 & 0.847 \\
\hline Non-NeP antidepressants & 23.8 & 23.8 & 1.000 \\
\hline Steroids (systemic) & 15.9 & 15.9 & 1.000 \\
\hline Sedative/hypnotics & 15.8 & 13.7 & 0.348 \\
\hline Opioid analgesics - long-acting & 11.4 & 7.7 & 0.039 \\
\hline Non-NeP antiepileptics & 9.5 & 7.9 & 0.334 \\
\hline Topical analgesics & 4.0 & 3.8 & 0.876 \\
\hline \multicolumn{4}{|l|}{ SCl- and pain-related procedures, \% } \\
\hline Spinal cord surgery & 4.6 & 6.8 & 0.117 \\
\hline Spine decompression & 12.8 & 7.0 & 0.001 \\
\hline Stabilization of the spine & 10.4 & 6.2 & 0.012 \\
\hline Pain intervention procedure & 23.8 & 24.9 & 0.672 \\
\hline
\end{tabular}

Notes: ${ }^{2}$ Total proportion exceeds $100 \%$ since there is some overlap among the

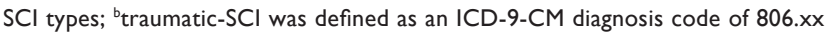
or $907.2 x$ at any time on or after the initial $\mathrm{SCl}$ diagnosis; 'count of unique three-digit ICD-9-CM codes on medical claims; ${ }^{d}$ count of unique outpatient medications; egastrointestinal conditions include irritable bowel syndrome, abdominal pain, gastroesophageal reflux disease, ulcers, neurogenic bowel, and constipation; 'respiratory conditions include respiratory failure, pulmonary embolism, pneumonia, and chronic obstructive pulmonary disease; ${ }^{\text {grenal/bladder }}$ conditions include neurogenic bladder, urinary tract infection, and urinary calculi.

Abbreviations: ICD-9-CM, International Classification of Diseases, Ninth Revision, Clinical Modification; NeP, neuropathic pain; NSAIDs, nonsteroidal antiinflammatory drugs; $\mathrm{SCl}$, spinal cord injury; SD, standard deviation. opioids most frequently reported $(86.8 \%)$, followed by anxiolytics (58.6\%); preindex use of these medications was $68.5 \%$ and $34.8 \%$, respectively. Also in contrast to the preindex period, medication utilization during follow-up was significantly higher in the SCI-NeP cohort relative to SCI only for every medication category (all $P<0.01$; Figure 1). The difference in proportion was greatest for muscle relaxants ( $58.6 \%$ versus $29.7 \%$ ), short-acting opioids $(86.8 \%$ versus $61.9 \%)$, and anxiolytics $(54.0 \%$ versus $31.0 \%$ ) while the magnitude of the difference was highest for topical analgesics $(9.2 \%$ versus $2.9 \%)$, long-acting analgesics (22.5\% versus $8.6 \%)$, and sedative/hypnotics $(34.1 \%$ versus $15.0 \%$ ).

In the SCI-NeP cohort, during the 12-month follow-up period, the most commonly used resource was outpatient medications, for which all patients had a claim, followed by physician office visits (93.4\%), and while almost twothirds (62.6\%) of this cohort had ED visits, only $34.6 \%$ had inpatient admissions (Table 4). As also shown in Table 4, HRU among the SCI-NeP patients was significantly higher relative to SCI-only patients for the proportion with ED visits, physician office visits, SCI- and pain-related procedures, and outpatient drug claims. Among patients with outpatient drug claims, medication utilization was significantly higher for SCI-NeP, with 67.6 (SD 54.2) claims per patient compared with 50.1 (SD 51.5) claims per patient for SCI only $(P<0.001)$. There were no differences between the cohorts for inpatient admissions or number of admissions per patient admitted, but there was a trend toward significance for the longer length of hospital stay that was observed in the SCI$\mathrm{NeP}$ cohort, 7.5 (SD 28.7) days versus 4.7 (SD 16.1) days $(P=0.050)$. Further adjustment of the covariates confirmed the lack of a difference between cohorts for hospitalizations, and further, found no difference in the rate of ED visits, even though the difference between the matched cohorts for the rate of ED visits was statistically significant.

As shown in Table 5, the mean (SD) all-cause total expenditures for SCI-NeP patients of $\$ 37,333(\$ 64,334)$ were higher than the $\$ 31,186(\$ 52,252)$ for SCI-only patients, but the difference was not significant $(P<0.083)$; median costs were $\$ 15,411$ and $\$ 11,477$, respectively. However, significantly higher expenditures were observed for several HRU categories including physician office visits, SCI- and pain-related outpatient services, and outpatient medications. The highest mean expenditures were for inpatient admissions (SCI-NeP, \$18,122 [\$55,828]; SCI only, $\$ 6,575[\$ 28,438] ; P=0.140)$. SCI- and pain-related outpatient 
SCI-NeP $(n=546) \quad \square$ SCI only $(n=546)$

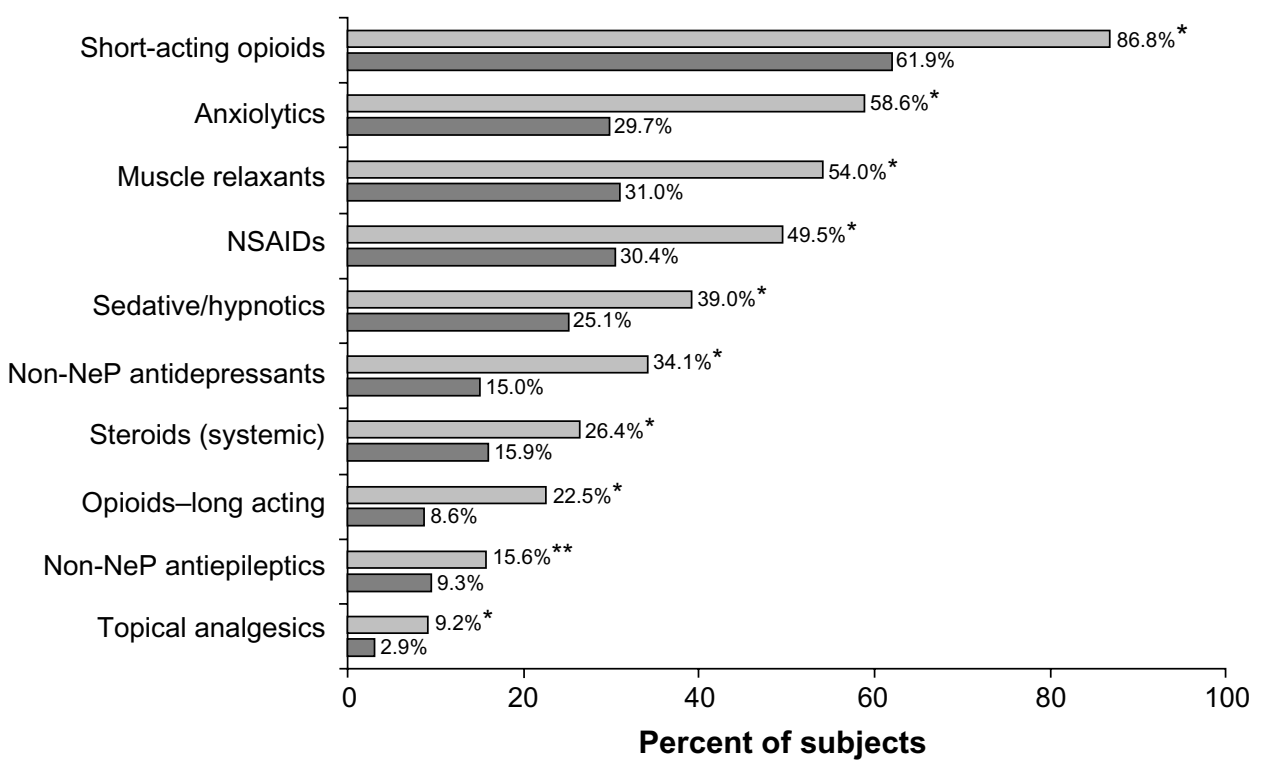

Figure I Medication utilization during the 12-month postindex follow-up period.

Note: $* P \leq 0.00 \mathrm{I}$ and $* * P<0.01$ versus $\mathrm{SCl}$ only.

Abbreviations: NeP, neuropathic pain; NSAIDs, nonsteroidal anti-inflammatory drugs; SCl, spinal cord injury; SD, standard deviation.

visits and procedures averaged $\$ 3,543(\$ 9,829)$ per SCI-NeP patient and $\$ 1,702(\$ 5,703)$ per SCI-only patient $(P=0.010)$, and for outpatient prescriptions, the values were $\$ 4,433$ $(\$ 6,248)$ per SCI-NeP patient and $\$ 3,276(\$ 6,357)$ per SCIonly patient $(P=0.002)$. Outpatient prescriptions accounted

Table 4 All-cause, postindex health care resource utilization

\begin{tabular}{|c|c|c|c|}
\hline Resource type & $\begin{array}{l}\mathrm{SCl}-\mathrm{NeP} \\
\mathrm{n}=546\end{array}$ & $\begin{array}{l}\text { SCI only } \\
n=546\end{array}$ & $P$ \\
\hline \multicolumn{4}{|l|}{ Inpatient admissions } \\
\hline Patients with any admission, \% & 34.6 & 30.6 & 0.156 \\
\hline $\begin{array}{l}\text { Mean (SD) admissions per } \\
\text { patient admitted }\end{array}$ & $2.1(1.8)$ & $2.1(2.6)$ & 0.989 \\
\hline $\begin{array}{l}\text { Mean (SD) length of stay per } \\
\text { admission }\end{array}$ & $7.5(28.7)$ & $4.7(16.1)$ & 0.050 \\
\hline \multicolumn{4}{|l|}{ Emergency department visits } \\
\hline Patients with any visit, \% & 62.6 & 56.4 & 0.036 \\
\hline $\begin{array}{l}\text { Mean (SD) visits per patient } \\
\text { with visit }\end{array}$ & $4.0(5.9)$ & $3.6(4.1)$ & 0.257 \\
\hline \multicolumn{4}{|l|}{ Physician office visits } \\
\hline Patients with any visit, \% & 93.4 & 87.7 & 0.001 \\
\hline $\begin{array}{l}\text { Mean (SD) visits per patient } \\
\text { with visit }\end{array}$ & II.3 (8.7) & $8.3(7.8)$ & $<0.001$ \\
\hline \multicolumn{4}{|l|}{$\mathrm{SCl}$ and pain-related procedures } \\
\hline Patients with any visit, $\%$ & 60.8 & 47.4 & $<0.001$ \\
\hline $\begin{array}{l}\text { Mean (SD) visits per patient } \\
\text { with visit }\end{array}$ & $33.9(59.8)$ & $22.2(35.9)$ & 0.006 \\
\hline \multicolumn{4}{|l|}{ Outpatient drug claims } \\
\hline Patients with any drug claim, $\%$ & 100 & 93.0 & $<0.001$ \\
\hline $\begin{array}{l}\text { Mean (SD) claims per patient } \\
\text { with claim }\end{array}$ & $67.6(54.2)$ & $50.1(5 \mid .5)$ & $<0.001$ \\
\hline
\end{tabular}

Abbreviations: NeP, neuropathic pain; SCl, spinal cord injury; SD, standard deviation. for $11.9 \%$ of total expenditures for SCI-NeP and $10.5 \%$ for SCI only.

Mean all-cause expenditures estimated using the ordinary least squares model to further adjust for covariates were $\$ 47,518$ for SCI-NeP and $\$ 30,150$ for SCI only, resulting in a significant incremental economic burden of $\$ 17,369$ (95\% confidence interval $\$ 9,753$ to $\$ 25,555$; $P<0.0001)$ for SCI-NeP. Factors significantly associated with increased costs included preindex expenditures ( $P=0.005)$, quadriplegia $(P<0.001)$, paraplegia $(P<0.001)$, cauda equina syndrome $(P=0.032)$, trauma-related SCI $(P=0.026)$, DCI score $(P=0.004)$, and number of preindex outpatient drugs $(P<0.001)$. In contrast, factors associated with lower all-cause expenditures were health maintenance organization health plans $(P<0.001)$, preindex nonsteroidal anti-inflammatory drug (NSAID) use $(P=0.036)$, and spine decompression $(P=0.036)$.

\section{Discussion}

In addressing the need for characterizing the economic burden of SCI-NeP, a previous burden of illness study estimated direct medical costs of $\$ 8,636$ among patients with this condition. ${ }^{19}$ However, the estimated costs in that study, which was performed in the general population, were derived from survey questions specific to SCI-NeP. Consequently, the overall economic burden may be substantially underestimated, at least for the Medicaid population, relative to 
Table 5 All-cause, postindex health care expenditures

\begin{tabular}{|c|c|c|c|c|c|}
\hline \multirow[t]{2}{*}{ Resource type } & \multicolumn{2}{|l|}{ SCI-NeP $(n=546)$} & \multicolumn{2}{|l|}{ SCI only $(n=546)$} & \multirow[t]{2}{*}{$P^{a}$} \\
\hline & Mean (SD) & Median & Mean (SD) & Median & \\
\hline Inpatient admissions, all patients & $\$ 18,122(\$ 55,828)$ & $\$ 0$ & $\$ 13,69 \mid(\$ 42,384)$ & $\$ 0$ & 0.140 \\
\hline Emergency department, all patients & $\$ 788(\$ 2,320)$ & $\$ 201$ & $\$ 598(\$ 1,217)$ & $\$ 78$ & 0.091 \\
\hline Physician office visits & $\$ 643(\$ 692)$ & $\$ 506$ & $\$ 444(\$ 513)$ & $\$ 276$ & $<0.001$ \\
\hline $\mathrm{SCl}$ - and pain-related outpatient services & $\$ 3,543(\$ 9,829)$ & $\$ 129$ & $\$ 1,702(\$ 5,703)$ & $\$ 0$ & $<0.001$ \\
\hline Total outpatient medical expenditures ${ }^{\mathrm{b}}$ & $\$ 14,777(\$ 18,856)$ & $\$ 7,706$ & $\$ 14,218(\$ 22,424)$ & $\$ 5,000$ & 0.656 \\
\hline Outpatient prescriptions & $\$ 4,433(\$ 6,248)$ & $\$ 2,292$ & $\$ 3,276(\$ 6,357)$ & $\$ 938$ & 0.002 \\
\hline Total health care expenditures ${ }^{c}$ & $\$ 37,333(\$ 64,334)$ & $\$|5,4| \mid$ & $\$ 31,186(\$ 52,252)$ & $\$ 11,477$ & 0.083 \\
\hline
\end{tabular}

Notes: aP-value is for difference in means between SCl-NeP and SCl only; bincludes emergency department visits, physician office visits, diagnostic testing, outpatient surgical procedures, and all other outpatient services; 'total of inpatient admissions, outpatient medical expenditures, and outpatient prescriptions. The currency used is $20 \mathrm{I} 2$ US dollars. Abbreviations: $\mathrm{NeP}$, neuropathic pain; SCl, spinal cord injury; SD, standard deviation.

the all-cause expenditures of $\$ 47,518$ reported here, and the incremental difference of $\$ 17,368$ compared with SCI patients without NeP. These excess expenditures resulted from greater HRU and associated costs among the SCI$\mathrm{NeP}$ patients during the 12-month follow-up period, and were observed despite the matching at baseline for demographic and clinical characteristics. While higher HRU and costs with SCI-NeP may not be surprising, this is the first study to describe such an economic burden in a Medicaid population.

SCI generally results in an array of medical and psychological issues, including depression, anxiety, muscle spasms, gastrointestinal, genitourinary, and other visceral problems, as were found in the preindex comorbidities and concomitant medications of both the SCI-NeP and SCI-only cohorts (Table 3). 3,21,29,30 While these study populations were well matched for preindex comorbid burden, especially notable was the postindex medication burden, with significantly higher prescription medication utilization overall in the SCI$\mathrm{NeP}$ cohort, particularly for medications used in pain management such as long- and short-acting opioids, anxiolytics, NSAIDs, and topical analgesics. Berger et $\mathrm{al}^{31}$ had raised a concern in their 2004 study of painful neuropathic disorders that patients with high comorbid burdens typically receiving pain-related opioids and NSAIDs may not be receiving optimal treatment. The increased use of these medications by SCI-NeP patients, as well as the other medication classes such as muscle relaxants, sedatives, non-NeP-related antidepressants and systemic steroids, provides evidence of the need for a more encompassing approach to treatment by recognizing the multifactorial nature of pain following SCI. Importantly, substance abuse was found preindex in more than one-quarter of each cohort, $28.2 \%$ of SCI-NeP and $26.7 \%$ of SCI-only patients. These proportions are higher than the $7.6 \%$ reported among the 5.0 million patients in the entire MarketScan Multi-state Medicaid Database using claims from July 2007 through June 2012. The particularly high rate of substance abuse across both SCI cohorts supports the need in these patients for a multimodal approach that includes greater use of nonopioid pharmacotherapy.

The adjusted economic burden of SCI-NeP during the year following $\mathrm{NeP}$ diagnosis $(\$ 47,518)$ was higher than that of SCI-only patients $(\$ 30,149)$, representing a significant incremental burden of $\$ 17,369$. In both cohorts, the primary driver of total expenditures was inpatient admissions while the main driver of outpatient costs was outpatient prescriptions. These values also evince the generally high cost of SCI, with and without NeP, as they are both higher than the $\$ 15,749$ per person that was reported as the average annual payment to the 8.8 million disabled Medicaid recipients (representing 19\% of all Medicaid beneficiaries) according to the 2011 Centers for Medicare \& Medicaid Services supplement, and higher than the mean cost of $\$ 21,450$ (range $\$ 17,561$ to $\$ 28,334$ depending on level and completeness of SCI) in a 2007 Veterans Health Administration study of SCI. ${ }^{18,20}$

A strength of this study is its use of propensity score matching, which resulted in cohorts with very few differences preindex. This matching increased the likelihood that the differences in HRU and costs observed during follow-up are due to the onset of $\mathrm{NeP}$, the distinguishing difference between the cohorts at the index event. The results were further confirmed using statistical modeling to provide an additional level of robustness by accounting for covariates that may have had effects beyond their impact on the propensity score.

Nevertheless, results of this study should be interpreted within the context of its limitations. Because absolute causality cannot be determined, including any inferences on the effects of $\mathrm{NeP}$ and comorbidities on resource utilization and expenditures, the observed relationships should be considered associative. Moreover, the similarity between groups was based on observed covariates that were considered potential confounders or risk factors and that were incorporated into the models. However, it is also possible that there were 
covariates that were not observed and therefore not incorporated into the models. In terms of potential measurement misclassification, the use of claims is also associated with the potential for misclassifying, undercoding, or overcoding the diagnoses of interest.

The use of AEDs and antidepressants as proxies to identify NeP represents another limitation, and despite excluding conditions for which these medications are approved for use, it is still possible that prescription of these medications after SCI diagnosis may not have been related to NeP. However, it is important to note that the need for such a proxy was due to a virtual lack of use of ICD-9-CM code 338.0x, and use of these drugs during the pre-SCI period was an exclusionary criterion to reduce the likelihood that they were prescribed for reasons other than NeP. While excluding patients with depression would have reduced this likelihood, this was not done since it would have further risked biasing the study populations.

Additionally, the data did not specify whether NeP was classified as at-level or below-level, which may be relevant from the clinical perspective since different treatment modalities may be used if the pain is at-level versus below-level. ${ }^{6,8}$ Similarly, the NeP itself may not have been related to SCI. However, this study required both that the SCI diagnosis precedes the first NeP diagnosis, and that there was no evidence of NeP within the 6-month period prior to SCI. These requirements are supported by previous studies showing that of $64 \%$ of patients reporting pain at 6 months and $81 \%$ within 12 months, $60 \%$ reported $\mathrm{NeP}^{32,33}$ While this study required an SCI diagnosis within 12 months prior to the first NeP diagnosis, the original SCI injury date as well as other diagnoses or procedures associated with SCI may have occurred prior to our period of observation.

Prescription claims data cannot be linked with specific diagnoses, and therefore our definition of NeP-related medications may be over or underrepresented. Finally, this analysis focused on a sample of US Medicaid beneficiaries, the results of which may not be generalizable to the overall US Medicaid population.

\section{Conclusion}

This study suggests the magnitude of the economic burden associated with $\mathrm{NeP}$ in patients with SCI in a Medicaid population, with estimated annual expenditures of $\$ 47,518$ per patient during the year following NeP onset. These expenditures result from use of a variety of health care resources in high proportions of patients, and the overall burden with regard to both HRU and costs is significantly greater than among SCI patients without NeP. Future research is warranted to explore differences between SCI patients who develop NeP and those who do not to garner further evidence for developing an effective multifactorial approach to treating patients with SCI-associated NeP.

\section{Acknowledgments}

The authors wish to acknowledge the key contributions of George Shrady (Truven Health Analytics) whose tireless work in defining, extracting, assembling, and analyzing the data made this research possible. Editorial support for this manuscript was provided by E Jay Bienen.

\section{Disclosure}

This study was sponsored by Pfizer Inc., New York, NY, USA and conducted by Truven Health Analytics, Washington, DC, USA. Jay Margolis and Paul Juneau are employees of Truven Health Analytics, who were paid by Pfizer Inc., in connection with the conduct of the study and development of this manuscript. Editorial support for this manuscript was provided by E Jay Bienen who was compensated by Truven Health Analytics. Thomas Bryce and Edward Nieshoff were not financially compensated for their collaboration on this project or for the development of this manuscript. Alesia Sadosky and Joseph Cappelleri are employees of Pfizer Inc. The authors report no other conflicts of interest in this work.

\section{References}

1. National Spinal Cord Injury Statistical Center. Spinal Cord Injury Facts and Figures at a Glance. Burmingham: National Spinal Cord Injury Statistical Center; 2013. Available from: https://www.nscisc.uab.edu/ PublicDocuments/fact_figures_docs/Facts\%202013.pdf. Accessed August 22, 2013.

2. Dijkers M, Bryce T, Zanca J. Prevalence of chronic pain after traumatic spinal cord injury: a systematic review. J Rehabil Res Dev. 2009;46(1): 13-29.

3. Ataoğlu E, Tiftik T, Kara M, Tunç H, Ersöz M, Akkuş S. Effects of chronic pain on quality of life and depression in patients with spinal cord injury. Spinal Cord. 2013;51(1):23-26.

4. Henwood P, Ellis JA. Chronic neuropathic pain in spinal cord injury: the patient's perspective. Pain Res Manag. 2004;9(1):39-45.

5. Bryce TN, Biering-Sørensen F, Finnerup NB, et al. International spinal cord injury pain classification: part I. Background and description. March 6-7, 2009. Spinal Cord. 2012;50(6):413-417.

6. Baastrup C, Finnerup NB. Pharmacological management of neuropathic pain following spinal cord injury. CNS Drugs. 2008;22(6):455-475.

7. Siddall PJ, McClelland JM, Rutkowski SB, Cousins MJ. A longitudinal study of the prevalence and characteristics of pain in the first 5 years following spinal cord injury. Pain. 2003;103(3):249-257.

8. Siddall PJ. Management of neuropathic pain following spinal cord injury: now and in the future. Spinal Cord. 2009;47(5):352-359.

9. Teasell RW, Mehta S, Aubut JA, et al; Spinal Cord Injury Rehabilitation Evidence Research Team. A systematic review of pharmacologic treatments of pain after spinal cord injury. Arch Phys Med Rehabil. 2010;91(5):816-831. 
10. Dworkin RH, O’Connor AB, Backonja M, et al. Pharmacologic management of neuropathic pain: evidence-based recommendations. Pain. 2007;132(3):237-251.

11. Attal N, Cruccu G, Baron R, et al; European Federation of Neurological Societies. EFNS guidelines on the pharmacological treatment of neuropathic pain: 2010 revision. Eur J Neurol. 2010;17(9): 1113-e88.

12. Lyrica ${ }^{\circledR}$ (pregabalin) capsules [prescribing information]. New York, NY: Pfizer, Inc.; 2012.

13. Priebe MM, Chiodo AE, Scelza WM, Kirshblum SC, Wuermser LA, Ho CH. Spinal cord injury medicine. 6. Economic and societal issues in spinal cord injury. Arch Phys Med Rehabil. 2007;88(3 Suppl 1): S84-S88.

14. Dryden DM, Saunders LD, Jacobs P, et al. Direct health care costs after traumatic spinal cord injury. J Trauma. 2005;59(2):443-449.

15. Cao Y, Chen Y, DeVivo M. Lifetime direct costs after spinal cord injury. Top Spinal Cord Inj Rehabil. 2011;16(4):10-16.

16. DeVivo M, Chen Y, Mennemeyer ST, Deutsch A. Cost of care following spinal cord injury. Top Spinal Cord Inj Rehabil. 2011;16(4):1-9.

17. Krueger H, Noonan VK, Trenaman LM, Joshi P, Rivers CS. The economic burden of traumatic spinal cord injury in Canada. Chronic Dis Inj Can. 2013;33(3):113-122.

18. French DD, Campbell RR, Sabharwal S, Nelson AL, Palacios PA, Gavin-Dreschnack D. Health care costs for patients with chronic spinal cord injury in the Veterans Health Administration. J Spinal Cord Med. 2007;30(5):477-481.

19. Mann R, Schaefer C, Sadosky A, et al. Burden of spinal cord injuryrelated neuropathic pain in the United States: retrospective chart review and cross-sectional survey. Spinal Cord. 2013;51(7):564-570.

20. Centers for Medicare \& Medicaid Services and Department of Health and Human Services. Brief Summaries of Medicare \& Medicaid. Baltimore, MD; 2011. Available from: https://www.cms.gov/ResearchStatistics-Data-and-Systems/Statistics-Trends-and-Reports/MedicareProgramRatesStats/downloads/MedicareMedicaidSummaries2011.pdf. Accessed June 11, 2014

21. Finnerup NB, Jensen TS. Spinal cord injury pain - mechanisms and treatment. Eur J Neurology. 2004;11(2):73-82.
22. Rosenbaum PR, Rubin DB. The central role of the propensity score in observational studies for causal effects. Biometrika. 1983;70(1): 41-55.

23. Deyo RA, Cherkin DC, Ciol MA. Adapting a clinical comorbidity index for use with ICD-9-CM administrative databases. J Clin Epidemiol. 1992;45(6):613-619.

24. Austin PC. An introduction to propensity score methods for reducing the effects of confounding in observational studies. Multivariate Behav Res. 2011;46(3):399-424.

25. Hagen EM, Rekand T, Gilhus NE, Gronning M. Diagnostic coding accuracy for traumatic spinal cord injuries. Spinal Cord. 2009;47(5): $367-371$.

26. United States Department of Labor Bureau of Labor Statistics. http:// www.bls.gov/cpi/cpid1305.pdf. Accessed May 2, 2013.

27. Khan A, Ullah S, Nitz J. Statistical modelling of falls count data with excess zeros. Inj Prev. 2011;17(4):266-270.

28. Duan N. Smearing estimate: a nonparametric retransformation method. J Am Stat Assoc. 1983;78(3838):605-610.

29. Middleton JW, Lim K, Taylor L, Soden R, Rutkowski S. Patterns of morbidity and rehospitalisation following spinal cord injury. Spinal Cord. 2004;42(6):359-367.

30. Jensen MP, Truitt AR, Schomer KG, Yorkston KM, Baylor C, Molton IR. Frequency and age effects of secondary health conditions in individuals with spinal cord injury: a scoping review. Spinal Cord. 2013;51(12):882-892.

31. Berger A, Dukes EM, Oster G. Clinical characteristics and economic costs of patients with painful neuropathic disorders. J Pain. 2004;5(3):143-149.

32. Siddall PJ, Taylor DA, McClelland JM, Rutkowski SB, Cousins MJ. Pain report and the relationship of pain to physical factors in the first 6 months following spinal cord injury. Pain. 1999;81(1-2):187-197.

33. Bryce TN. Pain management in persons with spinal cord injury. In: Lin VW, editor. Spinal Cord Medicine. Principles and Practice. 2nd ed. New York, NY: Demos Medical Publishing; 2010.
Journal of Pain Research

\section{Publish your work in this journal}

The Journal of Pain Research is an international, peer-reviewed, open access, online journal that welcomes laboratory and clinical findings in the fields of pain research and the prevention and management of pain. Original research, reviews, symposium reports, hypothesis formation and commentaries are all considered for publication.

\section{Dovepress}

The manuscript management system is completely online and includes a very quick and fair peer-review system, which is all easy to use. Visit http://www.dovepress.com/testimonials.php to read real quotes from published authors. 